\title{
Psicodiagnóstico Tradicional e Interventivo: Confronto de Paradigmas?
}

\author{
Valéria Barbieri ${ }^{1}$ \\ Universidade de São Paulo (Ribeirão Preto)
}

\begin{abstract}
RESUMO - A atividade psicodiagnóstica é valorizada na Psicologia por sustentar seu status científico e fundamentar a identidade profissional. Embora o Psicodiagnóstico Tradicional contraponha atividades avaliativas e terapêuticas, o Psicodiagnóstico Interventivo as aproximou, modificação que acarretou consequências epistemológicas e metodológicas. O presente estudo examinou essa alteração e suas consequências para o status científico da Psicologia e para a identidade profissional. Para tanto, realizou-se uma exposição dos paradigmas quantitativo e qualitativo de investigação e uma análise dos fundamentos epistemológicos e metodológicos dessas duas práticas. As conclusões revelam que o Psicodiagnóstico Interventivo encontrase coerentemente baseado na perspectiva qualitativa, ao contrário do Tradicional, que apresenta embates paradigmáticos internos. Diante disso, o Psicodiagnóstico Interventivo oferece aos psicólogos um modelo de identificação profissional mais sólido que o Tradicional.
\end{abstract}

Palavras-chave: epistemologia; metodologia; ciência; psicodiagnóstico tradicional; psicodiagnóstico interventivo.

\section{Traditional Psychodiagnosis and Therapeutic Assessment: Paradigms Confrontation?}

\begin{abstract}
Psychodiagnostic activity is appreciated in Psychology for sustaining its scientific status and supporting the professional's identity. Although the Tradicional Psychodiagnosis contrasts diagnostic and therapeutic activities, the Therapeutic Assessment has approximated them. This change has generated epistemological and methodological consequences. The present study analyzed such a change and its consequences to Psychology's scientific status and professional's identity. To achieve this goal, a presentation of the quantitative and qualitative investigation paradigms and an examination of the epistemological and methodological foundations of those practices were accomplished. The conclusions show that the Therapeutic Assessment is coherently founded on the qualitative approach, in contrast to the Traditional Psychodiagnosis that presents internal paradigmatic contradictions. Given this, the Therapeutic Assessment offers psychologists a more solid basis for professional identification than the Traditional Assessment.
\end{abstract}

Keywords: epistemology; methodology; science; traditional psychodiagnosis; therapeutic assessment.

A atividade diagnóstica destaca-se na Psicologia por duas razões: (a) garante o status científico dessa área de conhecimento por empregar instrumentos que atendem exigências de padronização; (b) constitui o marco distintivo da identidade profissional do psicólogo, pelo caráter privativo do uso de testes psicológicos.

Em Psicologia Clínica, o diagnóstico é um passo anterior à psicoterapia, tendo como objetivo investigar os recursos e dificuldades do indivíduo e indicar a intervenção apropriada. Embora tenha pontos de contato com a psicoterapia (e.g., identificação dos conflitos nodais da personalidade, consideração de uma complexa interação dinâmica de variáveis) apresenta marcada diferença com ela, uma vez que intervenções terapêuticas não fazem parte do seu processo. Nesse sentido, a sessão destinada à devolução dos resultados tem um intuito principalmente informativo, embora nela possam sobrevir, de maneira involuntária, efeitos terapêuticos.

1 Endereço para correspondência: Departamento de Psicologia e Educação, Faculdade de Filosofia, Ciências e Letras de Ribeirão Preto, Universidade de São Paulo (FFCLRP-USP), Bloco 5. Av. Bandeirantes, 3900, Monte Alegre, Campus Universitário. Ribeirão Preto, SP. CEP 14040-901. Fone: (16) 360237 98.E-mail: valeriabarbieri@uol.com. br; valeriab@ffclrp.usp.br.
Essas ocorrências levaram profissionais e pesquisadores a se interessarem pelos mecanismos terapêuticos presentes na avaliação psicológica, surgindo investigações sobre sua potencialização e viabilidade de atualização. Nasceu assim o Psicodiagnóstico Interventivo (ou Avaliação Terapêutica), cuja principal característica é a realização de intervenções (assinalamentos, interpretações, holding) durante as entrevistas e aplicações de técnicas projetivas.

Essa variação em relação ao Psicodiagnóstico Tradicional acarreta modificações nesse processo que extrapolam o âmbito prático, alcançando o ético, o teórico, o metodológico e o epistemológico. Essas modificações devem ser examinadas minuciosamente a fim de avaliar se o Psicodiagnóstico Interventivo pode ser considerado uma vertente do Tradicional ou está se constituindo como campo de trabalho diverso.

Nesses termos, este estudo visa examinar as diferenças e semelhanças entre o Psicodiagnóstico Tradicional e o Interventivo em termos de seus fundamentos epistemológicos e metodológicos. Tal análise terá como objetivo averiguar se o Psicodiagnóstico Interventivo comprometeria a consideração da Psicologia como ciência e se agiria como fator desintegrador da identidade profissional do psicólogo. Para tanto, serão expostos e debatidos os fundamentos filosóficos 
dos paradigmas quantitativo e qualitativo, as peculiaridades metodológicas das pesquisas vinculadas a eles e as atuais posições quanto às suas possibilidades de integração. Em seguida serão apresentadas as características e formas de organização do Psicodiagnóstico Tradicional e do Interventivo, e analisados os seus pressupostos epistemológicos e metodológicos. Por fim, será efetuada uma comparação entre eles à luz do debate anterior.

\section{Paradigmas Quantitativo e Qualitativo de Investigação Científica: Epistemologia}

A relação correntemente estabelecida entre as perspectivas qualitativa e quantitativa de investigação é de rivalidade, o que conduz a um debate teórico em que uma só se define por oposição à outra (Davila, 1995). Esse antagonismo foi criticado por Gutiérrez e Delgado (1995) e por Conde (1995a, 1995b), por transformar em simples discussão metodológica o que seria, na verdade, duas abordagens diferentes de construção da realidade. Assim, as técnicas e práticas de investigação próprias de cada perspectiva não rastreiam um fenômeno que ‘já estava lá, esperando para ser descoberto', mas edificam resultados, produtos e níveis diferentes do real (Gutiérrez \& Delgado, 1995). Evidentemente, isso não significa que os paradigmas não devam ser continuamente questionados quanto à sua validade, rigor, utilidade e aplicabilidade.

Um paradigma é definido como um conjunto de modelos de investigação que inclui lei, teoria, aplicação e instrumentos de pesquisa (Pacheco Filho, 2000a). Ele estabelece uma série de definições, entre elas quais seriam os fenômenos passíveis de investigação (os que podem ser traduzidos para a linguagem do paradigma), os métodos e técnicas para fazê-lo, além dos conceitos a serem utilizados na interpretação dos dados. Assim, haveria um direcionamento da pesquisa para aquilo que o paradigma considera importante e, com exceção de uma faixa pequena de variação, os resultados das pesquisas permaneceriam dentro de uma margem de previsibilidade.

Dessa maneira, qualquer perspectiva de investigação, quantitativa ou qualitativa, parte de pressupostos que conformam e restringem o significado dos dados e, em consequência, as conclusões que adviriam deles. Nos termos de McGrath e Johnson (2003), a metodologia faz o significado, já que tudo aquilo que nós 'sabemos', nós apenas o sabemos no contexto das pressuposições dos paradigmas e dos instrumentos de coleta de dados privilegiados por eles. Como os paradigmas são constituídos no contexto de determinantes históricos, políticos, socioeconômicos e culturais, é necessário considerar suas características metodológicas no seio desses determinantes.

\section{Contextualização Histórico-Filosófica dos Paradigmas Quantitativo e Qualitativo}

Embora Conde (1995a) situe as origens das perspectivas quantitativa e qualitativa nos pensamentos de Platão e Aristóteles, respectivamente, as raízes da primeira podem ser retroagidas até a filosofia pré-socrática de Pitágoras, que preconizava a redução dos fenômenos empíricos à matemática. A despeito dessa origem longínqua, foi somente no
Renascimento que a perspectiva quantitativa floresceu. No contexto sócio-histórico da queda do feudalismo e ascensão da burguesia, implicando que a ordem social era dinâmica e não estática, os dogmas da Igreja foram postos em questão, surgindo preocupações com o desenvolvimento de métodos de produção e avaliação da legitimidade do conhecimento, que ultrapassassem as distorções introduzidas pela falibilidade humana.

Do ponto de vista da filosofia da ciência, os fundamentos da perspectiva quantitativa também podem ser remetidos ao positivismo lógico do chamado primeiro círculo de Viena (Proctor, 2005). Seu pressuposto era o de que existia um mundo material ordenado, fixo e cognoscível via raciocínio disciplinado e aplicação correta e sistemática de uma metodologia específica (Hanson \& Grimmer, 2007); com isso, o caminho a trilhar para ascender dos dados empíricos até as leis gerais sobre a natureza (método) ocupou lugar de destaque (Pacheco Filho, 2000b). Os fenômenos sociais e psicológicos teriam uma realidade concreta e independente do pesquisador (objetivismo) e suas relações seriam investigadas em termos de efeitos causais. Nesse sentido, as abordagens quantitativas adotariam uma metodologia nomotética, por sua característica de coletar e assimilar os fatos visando formular leis imutáveis e universalmente aplicáveis, ou seja, generalizar (Gelo, Braakmann \& Benetka, 2008).

A preocupação com a objetividade tornou-se importante, e sua determinação exigia procedimentos que impedissem ou diminuíssem a necessidade do julgamento. Conceitos como fidedignidade, validade e significância estatística passaram a ser usados criteriosamente, com o propósito de descrever partes da realidade com certo grau de certeza (Hanson \& Grimmer, 2007). Os pesquisadores seriam espectadores objetivos da natureza, isentos da influência de suas leis, o que lhes conferia um status epistemológico superior ao dos sujeitos/objetos de estudo. Os instrumentos deveriam permitir a medição dos fenômenos, o que forneceria insight sobre a natureza essencial da realidade (matemática). Os experimentos, que haviam sido introduzidos por Galileu, tornaram-se o ideal metodológico da pesquisa científica (Conde, 1995a) que privilegiava a validade interna do conhecimento (produzido nos laboratórios) em detrimento da externa (transposição do conhecimento para o mundo concreto).

Por sua vez, o paradigma qualitativo, conforme originado no pensamento de Aristóteles, preconizava uma aproximação da natureza no que ela possuía de mais sensível e concreto, propondo como método para a sua averiguação a observação, a descrição e a comparação de exemplares. Assim, ele é compatível com uma metodologia idiográfica (Gelo \& cols., 2008; Hanson \& Grimmer, 2007), que busca a representação de um evento singular, de uma realidade temporalmente limitada, visando compreender o fenômeno em sua factualidade.

A despeito de apresentar origens na Antiguidade, a possibilidade de fazer pesquisa qualitativa tornou-se uma realidade somente a partir da década de 1960, com o interesse no pluralismo epistemológico, metodológico e cultural. $\mathrm{O}$ descontentamento com os rumos positivistas que tomava a investigação dos fenômenos sociais levou vários cientistas a proporem uma abordagem contextualizada e holística dos seres humanos. As visões de mundo subjacentes a essa perspectiva incluíam o subjetivismo, que concebe a expe- 
riência subjetiva como fundamental em qualquer processo de conhecimento, e o construcionismo, que considera o conhecimento como uma construção resultante da interação entre os indivíduos e o mundo social (Gelo \& cols., 2008). Observar, descrever e compreender tornaram-se as novas palavras de ordem, e o empreendimento do cientista passou a ser a construção e geração do conhecimento, ao invés da confirmação ou refutação de hipóteses (Bamberg, 2003).

Os alicerces da abordagem qualitativa integram as tradições filosóficas da Fenomenologia (estudo do fenômeno mental conforme experimentado pela própria pessoa), da Hermenêutica (compreensão dos fenômenos a partir do ponto de vista do outro) e do Interacionismo Simbólico (consideração da ação humana como baseada em significados construídos na interação social) (Gelo \& cols., 2008).

De acordo com essas fundamentações, foi atribuído um papel central aos sujeitos da pesquisa (agora chamados 'participantes'), às suas experiências pessoais singulares e à sua relação com o pesquisador; ainda, o distanciamento afetivo do investigador foi considerado prejudicial para a compreensão do comportamento humano (McGrath \& Johnson, 2003). Com isso, houve uma redefinição do status dos dados colhidos, de sua análise e interpretação, bem como do que poderia contar como conhecimento: este passou a ter como objetivo não o controle e a predição, mas a expansão da capacidade humana para a ação, o seu potencial de transformação da realidade.

\section{Metodologias Quantitativa e Qualitativa de Investigação Científica}

Os pressupostos filosóficos das abordagens quantitativas e qualitativas de investigação se refletem em suas distintas metodologias, ou seja, no conjunto de regras, princípios e condições formais que guiam a investigação científica. Assim, os designs de pesquisa quantitativa e qualitativa variam, incluindo os métodos de seleção da amostra, coleta, análise e interpretação dos dados (Gelo \& cols. 2008).

Davila (1995) descreve a pesquisa quantitativa como sistematizada por uma série de passos sucessivos e organizados, cada um responsável pelo seguinte. Das hipóteses às conclusões haveria um conjunto de normas a seguir (método), com o início de uma investigação sendo o momento em que tudo se define. Essa rotinização de procedimentos causa a impressão de autonomia do processo, com o método adquirindo supremacia sobre o problema investigado, que deve ser moldado, contraído e distendido em sua função.

Já no enfoque qualitativo, o início da investigação não é o momento decisivo, mas apenas uma tarefa entre outras, todas passíveis de reformulações. Não se subentende uma padronização de procedimentos, pois é o objetivo final (transformação da realidade e produção de conhecimento socialmente útil) que os sobredetermina, tendo primazia sobre o método. Ele não visa o controle do fenômeno, mas sua compreensão, a busca do sentido da experiência vivida pelos participantes. Para tanto, o pesquisador examina os modos como as ações humanas e as identidades sociais estão localmente constituídas no fluxo de uma vida social e cultural (Marecek, 2003).

O tipo de conhecimento informado pelas perspectivas quantitativa e qualitativa diverge: a primeira gera a desco- berta de leis que regem uma realidade, visando sua generalização; a segunda gera significados, conceitos, novas teorias ou revisões de antigas. Quanto à definição da amostra, a perspectiva quantitativa busca atender o critério da representatividade estatística, o que torna a quantidade de sujeitos um tema importante. Já na abordagem qualitativa, trabalha-se com um único indivíduo ou com um grupo composto por pessoas que de fato estão juntas na realidade. O que se torna relevante não é o número de sujeitos, mas a natureza da composição do grupo, sendo os critérios de seleção empregados os de compreensão, pertinência e riqueza informativa (Gelo \& cols., 2008). Os sujeitos são vistos como autores do processo de construção do conhecimento, em colaboração com o pesquisador.

No que concerne aos procedimentos de coleta de dados, Conde (1995b) pondera que é o nível de realidade construído pelas perspectivas que dá sentido ao seu emprego. Desse modo, as diretrizes quantitativas requerem instrumentos capazes de medir uma variável específica da maneira mais pura possível (isolando-a dos efeitos do contexto), para identificar relações de causa e efeito em termos de seus determinantes proximais e imediatos. Acrescente-se que a escolha do instrumento também é definida em termos de sua adequação aos procedimentos de análise estatística a que os dados serão submetidos. Por sua vez, os instrumentos determinam o tipo de questões a serem pesquisadas, que devem ser passíveis de captação e mensuração por eles.

Já na pesquisa qualitativa, por seu compromisso de interrogar a subjetividade e sua ênfase na diversidade de respostas, uma situação é examinada por meio da coleta de dados de múltiplas e variadas fontes, com o pesquisador devendo determinar o que ela significa para os seus integrantes. Os instrumentos privilegiados são abertos, considerando que a melhor forma de alcançar uma visão mais adequada da pessoa completa é por meio da liberdade de expressão. Essa liberdade não significa que o pesquisador qualitativo inicie a sua empreitada sem pressuposições, já que a adoção de qualquer paradigma implica numa pré-definição dos fenômenos passíveis de investigação. Sem essas "teorias" ou "ideias" anteriores, ele não conseguiria selecionar quais de suas observações seriam consideradas como dados; mesmo assim, o emprego de métodos mais indutivos deixa o caminho aberto para o encontro com o novo e o inesperado. Contradizendo o princípio de que a conduta do examinador deve ser padronizada para minimizar sua influência nos resultados, no paradigma qualitativo ele tem um papel vital na coleta, análise e interpretação dos dados. No que concerne à coleta, os dados são criados conjuntamente por ele e pelos respondentes, sendo que o relacionamento entre ambos determina, em parte, aquilo que é dito (Kvale, 2003).

A análise dos resultados no paradigma quantitativo consiste em um passo posterior à coleta e visa descobrir relacionamentos causais entre variáveis. Assim, ela segue uma direção que vai do descritivo ao inferencial (Gelo \& cols., 2008). Já nas abordagens qualitativas, a análise acontece simultaneamente à coleta dos dados: a partir do momento em que entra em contato com a informação, o pesquisador a analisa e interpreta. Com isso, em todo momento são feitas devoluções ao indivíduo ou grupo em estudo, sendo que é o pesquisador que se constitui na unidade de investigação 
(Davila, 1995). Há, portanto, uma interação contínua entre avaliação e intervenção, cada uma se constituindo e sendo constituída pela outra. Essa simultaneidade não desobriga o cientista de se debruçar posteriormente sobre os dados, buscando maior sistematização deles (Barbieri, 2008). Nessa etapa, uma das principais dificuldades consiste em selecionar a partir da enorme quantidade de dados obtidos; contudo, a maior liberdade que o pesquisador dispõe permite considerar distinções refinadas, exceções e padrões complexos de relação entre eles. Os tipos mais comuns de análise realizados são a temática e a de conteúdo (Gelo \& cols., 2008).

Com relação às limitações de cada perspectiva de investigação, Gelo e cols. (2008) alertam que, no caso das metodologias quantitativas, a definição da medida como mera designação de números a objetos e eventos de acordo com regras específicas leva a uma codificação ambígua dos fenômenos mentais. Essa ambiguidade, acrescida às limitações dos procedimentos estatísticos, poderia acarretar dificuldades para obter um claro entendimento do fenômeno original no momento da análise (ontologia da variável) e para alcançar uma interpretação teórica significativa sobre ele e seus relacionamentos com outros fenômenos (epistemologia da variável). Rozin (2009), por sua vez, atenta que a sofisticação metodológica das abordagens quantitativas não deve suplantar o interesse pelo que as pessoas fazem no mundo real. Quanto à abordagem qualitativa, Yanchar, Gantt e Clay (2005) afirmam que ela também apresenta limites no que concerne ao estudo da experiência humana. Segundo eles, como o ponto focal das experiências muda durante o processo de reflexão, as pessoas nunca são capazes de examiná-las completamente no momento em que passam por elas. Em outras palavras, quando alguém é chamado a refletir sobre sua experiência, o foco muda da vivência concreta imediata para a análise dela, que geralmente ocorre de forma retrospectiva. Assim, persiste certo distanciamento tanto do participante com relação à própria experiência, quanto do investigador, que a compreende e a interpreta em função do paradigma que adota.

No que diz respeito à capacidade de generalização dos dados, McGrath e Johnson (2003) sustentam que tanto os estudos experimentais como os naturalísticos são fracos. Segundo eles, as investigações experimentais não podem reivindicar além dos sistemas artificiais nelas construídos. Do mesmo modo, as investigações qualitativas não podem afirmar além dos sistemas naturais incluídos em seus estudos.

Considerando as limitações das duas perspectivas, Ortí (1995) sustenta que elas devem manter uma relação de complementaridade por deficiência. Posição semelhante é defendida por Conde (1995b), que sugeriu a existência de um continuum entre ambas. Essa integração é endossada também por outros pesquisadores, que argumentam que a atitude de considerá-las como opostas leva a negligenciar seus aspectos comuns; por exemplo, ignora-se que mesmo os pesquisadores experimentais não se aferram ferozmente a hipóteses prévias, já que não é raro haver reformulação delas após uma análise preliminar dos dados (Marecek, 2003). Também o acordo intersubjetivo entre pesquisadores, uma das formas de calcular o nível de 'objetividade' do conhecimento, é compartilhado por ambas as perspectivas. Nesse sentido, muitas pesquisas misturam métodos e técnicas quantitativas e qualitativas (Hanson \& Grimmer, 2007).
Compartilhando dessa tendência à integração das perspectivas, Gelo e cols. (2008) descrevem uma nova abordagem que vem sendo desenvolvida nas últimas décadas, a Mixed Methods Research (MMR). Eles consideram que haveria quatro instâncias principais para a combinação dos dois paradigmas: (1) pensar dialeticamente sobre a integração deles; (2) usar um novo paradigma; (3) ser pragmático; e (4) colocar a compreensão substantiva em primeiro lugar (também conhecida como concept-driven research). Em termos dos delineamentos de pesquisas, os designs mais conhecidos da MMR seriam a triangulação (utilização, na mesma pesquisa, de métodos quantitativos e qualitativos, sem haver supremacia de um sobre o outro), o embutido (em que um conjunto de dados desempenha um papel secundário e de apoio para um estudo de outro tipo), o explanatório (que obtém dados quantitativos para depois explicá-los usando dados qualitativos) e o exploratório (uso de resultados qualitativos para informar resultados de um método quantitativo). O MMR apresenta procedimentos específicos para a definição da amostra, coleta, análise e interpretação dos dados, segundo o design do estudo e sua característica monofásica ou bifásica.

Outro representante da tendência à integração dos paradigmas é Proctor (2005). Ele sustenta que, embora os paradigmas pareçam manter uma unidade, as mudanças na ontologia, metodologia e epistemologia ocorrem de modo independente. Desse modo, ele defende uma abordagem naturalística da ciência, considerando que as afirmações sobre a metodologia e as práticas científicas não podem ser justificadas por argumentos ontológicos, mas devem ser avaliadas empiricamente, do mesmo modo que as hipóteses ou teorias, quanto à sua capacidade de permitir progressos.

Yanchar e cols. (2005), por sua vez, adotam a perspectiva da concept-driven research. Eles afirmam que pouco conhecimento científico genuíno tem sido gerado por meio da adoção rígida de qualquer um dos dois paradigmas, já que eles possibilitam certos tipos de compreensão, mas impedem outros, crítica válida também para o pluralismo metodológico. Como alternativa, eles propõem a chamada Metodologia Crítica, que envolve, além da reflexão e revisão dos métodos antigos, o desenvolvimento de novos, baseados nas exigências da exploração teórica e em sua autoavaliação crítica. Assim, eles recomendam uma atitude de esclarecer pressupostos filosóficos e explorar abordagens não ortodoxas e criativas para a pesquisa científica. Nesse caso, os métodos se tornariam orientados para a prática e se conformariam às sutilezas de questões específicas dentro de um programa de pesquisa. As inovações metodológicas seriam vistas como um processo que ocorre sincronicamente com um exame crítico e refinamento dos pressupostos básicos do pesquisador, temas da pesquisa e teoria.

A nosso ver, essas propostas de integração são ainda criticáveis, porque nenhuma delas resolveu a questão subjacente da contradição dos paradigmas. No caso da MMR, trabalha-se ao mesmo tempo com múltiplas visões de mundo nem sempre coerentes entre si, o que acarreta perda de solidez e de senso de unidade da pesquisa. Na perspectiva naturalística, o critério de ordem superior de valoração da pesquisa, de natureza exclusivamente empírica, é consistente com uma visão funcionalista do mundo, passível de promover não o avanço, mas o retrocesso do conhecimento científico. 
Finalmente, no que diz respeito à Metodologia Crítica, ela provoca somente um deslocamento da idolatria do método para a da teoria. Ainda, a proliferação de metodologias que essa abordagem fomenta é acompanhada do risco de que elas passem a fazer sentido somente no contexto de uma ou poucas teorias. Com isso, o diálogo científico e a possibilidade de avaliação da qualidade do conhecimento obtido ficam comprometidos. Diante dessa situação, sustentamos que a integração bem sucedida das abordagens metodológicas quantitativa e qualitativa deve ser necessariamente acompanhada por desenvolvimentos na filosofia da ciência, que até o momento não têm sido satisfatórios para promover uma fundamentação estável que sustente tal integração.

Marecek (2003) considera a complementaridade entre as duas abordagens como um mito, por torcer a discussão para um foco meramente metodológico. Camic, Rhodes e Yardley (2003) acrescentam que mesmo quando se trata somente de uma questão de método, as abordagens quantitativas e qualitativas podem produzir resultados contraditórios a respeito do mesmo fenômeno.

Embora cada paradigma tenha as suas virtudes e apresente problemas diferentes, mas igualmente sérios, a maior parte da Psicologia Acadêmica apresenta forte preferência pelas abordagens quantitativas (Aguinis, Pierce, Bosco \& Muslin, 2009; Ato \& Hox, 2009; Gelo \& cols., 2008; Hanson \& Grimmer, 2007; Rozin, 2009). Camic e cols. (2003) afirmam que, como profissão, a Psicologia geralmente considera que os números são mais reais do que as palavras, e que as respostas a testes tipo lápis e papel são mais verdadeiras do que às entrevistas.

Diante dessas considerações, e atentando para o fato de que o Psicodiagnóstico (Tradicional) é visto como um dos pilares que garantem a autenticidade científica da Psicologia, o exame de seus fundamentos e formas de realização sob a ótica dos paradigmas científicos discutidos é importante para averiguar a coerência dessa prática e as dificuldades que ela impõe.

\section{Psicodiagnóstico Tradicional: Definição, Objetivos e Organização}

O processo psicodiagnóstico aqui debatido refere-se àquele descrito por Ocampo, Arzeno e Piccolo (1979/1986), modelo mais difundido na América Latina. Ele resultou de uma série de modificações ao longo da história da Psicologia, iniciadas com a adoção, pelo psicólogo, do modelo médico, visando localizar nos protocolos dos testes sinais de patologias específicas ${ }^{2}$, até a incorporação do referencial psicanalítico em sua realização. De acordo com Ocampo e cols., essa incorporação deveria ser parcial, restrita à utilização de conceitos da Psicanálise para a interpretação do material produzido pelo paciente. A transposição da dinâmica do processo psicanalítico para a avaliação psicológica era energicamente reprovada, já que isso significava aceitar condutas do paciente como atrasos, silêncios e produções espontâneas, muitas vezes incompatíveis com a atitude

2 Ainda hoje a definição de sinais psicopatológicos nas técnicas de avaliação constitui um tema importante na literatura da área e uma prática regular entre profissionais. necessária para responder aos instrumentos de exame. Os settings avaliativo e terapêutico foram claramente diferenciados, o que implicava que no primeiro não havia lugar para intervenções. Os psicólogos que buscaram aproximar esses dois processos foram vistos como prestando um desserviço à profissão, acusados de distorcê-la devido à sua identificação com o psicanalista.

A compreensão de Ocampo e cols. (1979/1986) sobre o Psicodiagnóstico Tradicional foi sumariada por Cunha, Freitas e Raymundo (1986), que o definiram como um processo temporalmente limitado, que emprega métodos e técnicas psicológicas para compreender os problemas, avaliar, classificar e prever o curso do caso, culminando na comunicação dos resultados. Ele teria um caráter científico porque parte de um levantamento prévio de hipóteses, a serem confirmadas ou não por passos predeterminados, e seria estabelecido tão logo as entrevistas permitissem levantá-las. Ele teria como objetivo conseguir uma descrição e compreensão profunda e completa da personalidade do paciente, visando explicar a dinâmica do caso no material recolhido, integrando-o num quadro global para, a partir daí, formular recomendações terapêuticas.

Os passos necessários para alcançar esses objetivos seriam:

1) Entrevista inicial com o paciente, para conhecê-lo e extrair informações visando formular hipóteses para planejar a bateria de testes a aplicar. Tais hipóteses seriam traduzidas em forma de perguntas norteadoras do processo subsequente.

2) Aplicação de testes para investigar as hipóteses anteriores. Cunha e cols. (1986) concordam que os problemas do encaminhamento são reformulados pelo psicólogo em termos diretamente relacionados com as técnicas e métodos que utiliza. A bateria de testes deve ser aplicada em uma sequência específica, considerando o aspecto avaliado por cada um, seu nível de estruturação e caráter ansiogênico. Ocampo e cols. (1979/1986) afirmam que os testes projetivos são fundamentais na avaliação porque apresentam padronização, o que confere uma segurança importante ao diagnóstico.

3) Entrevista devolutiva, cujo objetivo é comunicar ao paciente o que se passa com ele e orientá-lo com relação à conduta a ser seguida. Ocampo e cols. (1979/1986) sustentam que a transmissão da informação é o objetivo básico dessa entrevista, mas, às vezes, ela adquire uma importância transcendental, quando nela surgem lembranças reprimidas ou atitudes inesperadas que podem alterar o plano tático antes construído.

4) No caso de encaminhamento, há redação de informe para o profissional remetente.

Com relação à coleta de dados na entrevista inicial, Cunha e cols. (1986) afirmam que dependendo dos objetivos do Psicodiagnóstico a abordagem se torna menos diretiva ou formal, porque se busca compreender a pessoa em relação com as circunstâncias e acontecimentos de sua vida presen- 
te e passada. Assim, visa-se descrever o problema atual e colocá-lo numa perspectiva histórica para apreender o seu significado dentro de um processo vital, num contexto temporal, afetivo e social.

Com referência aos potenciais efeitos terapêuticos da entrevista devolutiva, eles são considerados por Ocampo e cols. (1979/1986) como involuntários, já que o objetivo de todo o processo seria meramente o diagnóstico, e intervenções terapêuticas nesse momento seriam consideradas perigosas, podendo prejudicar o vínculo com o profissional e provocar abandono, por parte do paciente, pela ansiedade.

\section{Psicodiagnóstico Tradicional e Ciência}

A asserção de Cunha e cols. (1986) de que o Psicodiagnóstico é um processo científico porque parte de um levantamento de hipóteses a serem ou não confirmadas por meio do seguimento disciplinado de passos específicos (método) revela sua concepção no paradigma quantitativo de investigação (Davila, 1995; Hanson \& Grimmer, 2007). Esse trabalho permitiria ascender dos dados empíricos fornecidos pelo paciente até a sua classificação em categorias gerais (Gelo \& cols., 2008). A sistematização do processo em passos implica numa rotina de procedimentos que limita a liberdade do psicólogo, que fica restrita à escolha dos instrumentos que empregará.

A necessidade de traduzir as hipóteses levantadas na entrevista em termos do que os instrumentos podem responder requer a realização de recortes, adições, alongamentos, contrações e distorções na problemática apresentada pelo paciente. Assim, as técnicas de avaliação psicológica determinariam o que pode ser apreendido dos casos específicos. Nessa condição, em que a resposta está presente antes da pergunta, o conhecimento produzido permanece estático, repetitivo e deformado pelos ajustes que o fenômeno passou para adaptar-se ao que seria investigável pelas técnicas.

Ocampo e cols. (1979/1986) afirmam que os testes são importantes no Psicodiagnóstico por apresentarem padronização, ou seja, atenderem aos requisitos científicos dos instrumentos das abordagens quantitativas (Hanson \& Grimmer, 2007); tais características constituem-se em critérios primordiais de sua escolha, pressupondo que elas garantiriam o status científico do processo completo. Esses critérios também são exigidos das técnicas projetivas, mesmo ao custo da negação de suas raízes epistemológicas, já que seu berço paradigmático consiste na perspectiva clínico-qualitativa de investigação. Finalmente, a separação entre investigação e intervenção é outra semelhança entre o Psicodiagnóstico Tradicional e o paradigma quantitativo.

Contudo, é ilusório acreditar em uma identificação unívoca entre o Psicodiagnóstico Tradicional e a perspectiva quantitativa, uma vez que algumas de suas características opõem-se frontalmente aos pressupostos dessa abordagem. Nesse sentido, o reconhecimento de Cunha e cols. (1986) de que no Psicodiagnóstico existe uma grande complexidade de variáveis, comparável à da situação terapêutica, e a consideração de que o seu objetivo é obter uma descrição e compreensão profunda e completa do paciente está enrai- zado indiscutivelmente no paradigma qualitativo (Bamberg, 2003; Gelo \& cols., 2008). O alcance desse intuito, todavia, é incompatível com uma metodologia de comprovação/ refutação de hipóteses que prevê passos pré-definidos para o seu desenvolvimento, e com a mutilação dos problemas existentes na vida real para encaixá-los na cama de Procusto dos testes psicológicos.

Ainda, no Psicodiagnóstico Tradicional, a diretriz de que a escolha dos testes deve basear-se em critérios de validade e precisão estatísticas pressupõe buscar a avaliação de variáveis 'puras', isoladas do contexto de vida da pessoa, já que quanto maiores os índices de validade e precisão, maior seria essa 'pureza'. No entanto, no momento da síntese final, seus resultados devem ser inseridos no contexto de vida do indivíduo, de modo a informar sobre as relações deles com suas circunstâncias pessoais passadas e presentes (Cunha \& cols., 1986); enfim, novamente busca-se um objetivo qualitativo por meio de instrumentos quantitativamente padronizados. Quanto às técnicas projetivas, que permitem averiguar de modo mais coeso diversas variáveis em interação e, assim, ascender à singularidade do paciente, sua utilização permanece restrita à indicação dos níveis de integridade das funções egoicas, ou seja, à adaptação do indivíduo à realidade. Com isso, não se alcança o sentido psicológico da experiência, permanecendo-se num plano formal.

Diante dessa situação, muitos psicólogos dedicados à avaliação psicológica defendem que a combinação de técnicas quantitativas e qualitativas conferiria ao seu trabalho um caráter mais abrangente e uma compreensão mais completa do paciente. Contudo, esse argumento é sujeito às mesmas críticas atribuídas às propostas de integração das duas abordagens, já que persiste o problema da desarmonia na junção dos paradigmas devido à ausência do debate epistemológico. Tangenciando o âmbito paradigmático, a resolução das contradições é tentada no nível da operacionalização prática, basicamente no uso dos recursos do profissional, que se torna o elemento responsável por fazer uma articulação coesa daquilo que não pode ser integrado.

Em suma, o modo de organização e execução do Psicodiagnóstico Tradicional não permite atingir o seu objetivo de obter uma compreensão profunda, integrada e completa de uma pessoa em sua singularidade. Nesse contexto, não faz sentido opor os processos Psicodiagnóstico Tradicional e Interventivo em termos de suas diferenças de paradigmas, já que estes se embatem e se confrontam dentro do próprio modelo clássico de avaliação. Considerando que é exatamente essa prática contraditória que define a nossa identidade profissional, o psicólogo apareceria como uma sobreposição dissociada das identidades do médico, do físico e do psicanalista, ou seja, um falso Self.

\section{Psicodiagnóstico Interventivo}

Embora a prática do Psicodiagnóstico Interventivo tenha sido sistematizada na década de 1990, é possível encontrar menções a ela já em 1935, quando Morgan e Murray debateram o uso do Teste de Apercepção Temática (TAT) na psicoterapia, assunto que foi retomado por Bellak em 1974. Logo depois, Friedenthal (1976) propôs a aplicação 
do Teste de Relações Objetais (TRO) acompanhada por perguntas, assinalamentos e interpretações. Mais recentemente, destacam-se os trabalhos de Finn (1994), que se dedicou à 'Therapeutic Assessment' utilizando o Inventário Multifásico Minnesota de Personalidade - Forma 2 (MMPI-2) e, no Brasil, os de Ancona-Lopez e cols. (1995), num enfoque fenomenológico-existencial. Assim, existem maneiras diversas de realizar o Psicodiagnóstico Interventivo, baseadas em diferentes referenciais teóricos e/ou utilizando variados tipos de instrumento, não se podendo falar de uniformidade de procedimentos ou de unanimidade paradigmática.

O Psicodiagnóstico Interventivo abordado neste estudo é aquele concebido no contexto do referencial psicanalítico de compreensão da personalidade, instrumentalizado pelas técnicas projetivas e entrevista clínica. Ele começou a ser mais bem delineado no início do ano 2000 (Barbieri, 2002) e, a partir daí, novas contribuições não cessaram (Tardivo, 2006; A. M. T. Trinca, 2003; Vaisberg, 2004). É descendente do Psicodiagnóstico Compreensivo (W. Trinca, 1984) que abrange as dinâmicas intrapsíquicas, intrafamiliares e socioculturais como forças em interação, formando uma teia que pode resultar em sofrimento e desajuste. Essa trama conferiria um significado idiossincrático para a experiência do indivíduo e para o seu sintoma.

O Psicodiagnóstico Interventivo de orientação psicanalítica não se organiza em termos de passos a serem seguidos, mas de eixos estruturantes que compartilha com o Psicodiagnóstico Compreensivo:

1) Objetivo de elucidar o significado latente e as origens das perturbações;

2) Ênfase na dinâmica emocional inconsciente do paciente e de sua família;

3) Consideração de conjunto para o material clínico;

4) Busca de compreensão globalizada do paciente;

5) Seleção de aspectos centrais e nodais para a compreensão dos focos de angústia, das fantasias e mecanismos de defesa;

6) Predomínio do julgamento clínico, implicando no uso dos recursos mentais do psicólogo para avaliar a importância e o significado dos dados;

7) Subordinação do processo diagnóstico ao pensamento clínico: ao invés de existir um procedimento uniforme, a estruturação do psicodiagnóstico depende do tipo de pensamento clínico utilizado pelo profissional;

8) Prevalência de métodos e técnicas de exames fundamentados na associação livre, como entrevista clínica, observação, testes psicológicos utilizados como formas de entrevistas, cujos resultados são avaliados por meio da livre inspeção.

A adoção desses eixos permite alcançar a compreensão da pessoa em sua singularidade, o que é essencial para realizar intervenções. Portanto, há pouco lugar para interpretações oriundas dos estudos de padronização de testes psicológicos.

A realização de devolutivas não tem apenas o intuito de informar o paciente, como acontece no trabalho tradicional, mas de oferecer a ele uma experiência transformadora por meio do vínculo com o psicólogo, que coloque em marcha os seus processos de desenvolvimento.

\section{Psicodiagnóstico Interventivo e Ciência}

A descrição do Psicodiagnóstico Interventivo revela importantes semelhanças entre seus pressupostos e aqueles da perspectiva qualitativa de investigação científica.

O primeiro ponto em comum é a simultaneidade dos processos de avaliação e intervenção, ou de coleta e análise de dados (Barbieri, 2008; Davila, 1995). Assim, o conhecimento é construído de maneira conjunta no momento da interação entre o profissional/pesquisador e o paciente/participante, com o primeiro fazendo sua interpretação ${ }^{3}$ do material oferecido pelo segundo, que o aceita, rejeita, restringe ou amplia, reformando o que foi dito e devolvendo-o ao psicólogo, que efetua as revisões necessárias; assim, o paciente/participante colabora ativamente na geração do conhecimento. Essa cooperação se desenrola no contexto de uma relação profissional e, portanto, permanece qualitativamente assimétrica, mas não autoritária. Como coleta e análise ou avaliação e intervenção são constituídas uma pela outra, o procedimento não é isento do trabalho de levantamento de hipóteses pelo profissional, pois são elas que norteiam a intervenção, do mesmo modo que o pesquisador qualitativo também inicia seu trabalho com algumas pressuposições a respeito do fenômeno em investigação (Marecek, 2003). A diferença com relação ao Psicodiagnóstico Tradicional é que o apego às hipóteses não se mantém necessariamente por todo o processo, já que elas são colocadas à prova no momento de seu surgimento e, a partir daí, mantidas para aprofundamento, ganhando contornos diferentes, ou substituídas, não determinando, assim, o processo completo de avaliação. Portanto, similarmente às metodologias qualitativas, o início de um processo diagnóstico/interventivo não é o momento mais importante, mas apenas uma tarefa entre outras (Davila, 1995). Com isso, não há o estabelecimento sistemático de passos a serem seguidos e, consequentemente, o número de sessões não é definido de maneira precisa após a primeira entrevista. ${ }^{4}$

Os instrumentos menos estruturados de avaliação/intervenção, por permitirem uma apropriação pessoal por parte do paciente, possibilitam o alcance do sentido idiossincrático da sua experiência, objetivo também das pesquisas fundamentadas no paradigma qualitativo (Gelo \& cols., 2008; Marecek, 2003). Sua análise pelo método da livre inspeção viabiliza a apreensão da singularidade pessoal, ao invés de conformá-la aos moldes das interpretações advindas dos estudos de padronização. Desse modo, há a possibilidade de geração de novos conhecimentos e do encontro com o inesperado e

3 O termo "interpretação" é utilizado aqui em um sentido amplo, que inclui o psicanalítico, mas não se restringe a ele.

4 Os dados disponíveis até o momento sugerem que o número de sessões necessárias no Psicodiagnóstico Interventivo é diretamente proporcional à rigidez defensiva do paciente e inversamente proporcional à experiência clínica do psicólogo. 
mesmo com o velho, mas transformado e reformulado em função das diversas influências contextuais que recebe, e que lhe conferem um significado particular.

O psicólogo, na medida em que é quem integra o que se diz, torna-se, de fato (em conjunto com o paciente), o elemento mais importante da avaliação/intervenção. $\mathrm{O}$ risco de cair em um solipsismo ingênuo é contrabalançado pela participação do paciente no processo, que funciona como um controle da confiabilidade das intervenções; também é essa participação que facilita selecionar o material clinicamente significativo, retirando-o da esfera da consideração solitária do psicólogo. É somente nesse contexto de uma profunda compreensão individual que é possível expandir a ação humana e implementar uma conduta transformadora, objetivos tanto do Psicodiagnóstico Interventivo quanto da investigação qualitativa (McGrath \& Johnson, 2003).

Portanto, conforme o concebemos, o Psicodiagnóstico Interventivo de orientação psicanalítica aparece como coerentemente fundamentado no paradigma qualitativo de compreensão da realidade. Evidentemente, como campo novo e recém-constituído em nossa profissão, muito ainda deve ser ponderado em relação aos fundamentos desse método clínico, particularmente os de natureza teórica, técnica e ética, de modo a consolidá-lo cada vez mais, garantindo o seu lugar na ciência psicológica.

\section{Considerações Finais}

O nascimento do Psicodiagnóstico Interventivo implicou em reconsiderações de natureza paradigmática, metodológica, instrumental e ética em relação ao modelo tradicional, que o tornaram uma atividade bastante diferente da prática clássica. Assim, mais do que uma derivação do procedimento original, o Psicodiagnóstico Interventivo é um campo de conhecimento e aplicação clínica com características próprias.

Suas bases paradigmáticas qualitativas, coerentes com sua maior liberdade metodológica, a preferência por instrumentos pouco estruturados e o reconhecimento da influência do pesquisador/profissional na qualidade dos dados, fornecem fundamentos harmoniosamente integrados para a construção/ definição de uma identidade profissional sólida, em que objetivos científicos e éticos se encontram. Nesses termos, o que assistimos atualmente com o Psicodiagnóstico Interventivo é uma mudança dos valores relativos à fase inicial de articulação da Psicanálise ao Psicodiagnóstico, em que aqueles psicólogos que buscaram transpor o método psicanalítico para a situação de avaliação foram acusados de desvirtuar nossa identidade. Ao contrário, os argumentos expostos neste estudo permitem afirmar que, ao invés de constituir-se como agente desintegrador de nossa identidade, o Psicodiagnóstico Interventivo a fortalece e estabiliza.

As considerações deste artigo não permitem dizer que existe um confronto de paradigmas entre o Psicodiagnóstico Interventivo e o Tradicional. Essa impossibilidade decorre das contradições internas deste último, que fazem com que ele apresente alguns pontos de encontro com o primeiro e outros de franca oposição, que até o momento não parecem suficientes para situar essas duas formas de trabalho clínico e científico como rivais ou antagônicas. É preferível, portanto, considerá-las simplesmente como práticas diferentes, baseadas em concepções diversas de ciência, normalidade e patologia.

Embora o Psicodiagnóstico Interventivo seja um método mais recente que o Tradicional, consideramos que este último também carece de estudos relativos às suas bases epistemológicas e metodológicas, em função de seus embates internos. Essa observação remete à primeira questão que nos propusemos debater neste estudo, ou seja, até que ponto a prática do Psicodiagnóstico Interventivo comprometeria a consideração da Psicologia como ciência. Nossas ponderações mostram que este não é o caso, já que ele se fundamenta firmemente no paradigma qualitativo de investigação e, assim, proporciona a compreensão e a transformação do seu sujeito/objeto com a finalidade ética de reduzir o sofrimento humano. Portanto, ele se sustenta numa concepção de ciência que vai além da ênfase na experimentação que visa o controle e a predição.

O domínio da perspectiva quantitativo-positivista na Psicologia não deve inibir nossos movimentos em direção ao desenvolvimento dessa importante e promissora estratégia de pesquisa/intervenção. Nesse sentido, compactuamos com Lagache (1974), que afirma que o psicanalista não deve se sentir em posição inferior aos especialistas das outras ciências, nem se alienar na via de uma imitação servil delas. Foi na tentativa de aproximar-se das perspectivas quantitativas de investigação que o Psicodiagnóstico Tradicional se perdeu e, em decorrência disso, ofereceu-nos uma figura desarticulada como modelo de identificação. Nesse contexto, o Psicodiagnóstico Interventivo permite iniciar um novo capítulo na escrita de nossa identidade profissional, também local e temporalmente constituída e, por isso, em eterno processo de mudança.

\section{Referências}

Aguinis, H., Pierce, C., Bosco, F. A., \& Muslin, I. S. (2009). First decade of organizational research methods: Trends in design, measurement and data-analysis topics. Organizational Research Methods, 12, 69-112.

Ancona-Lopez, M., Vorcaro, A. M. R., Cupertino, C., Bruscagin, C. B., Barros, D. T. R., Yehia, G. Y., Santiago, M. D. E., AnconaLopez, S., Mito, T. I. H., \& Monachesi, Y. (1995). Psicodiagnóstico: processo de intervenção. São Paulo: Cortez.

Ato, M., \& Hox, J. (2009). Methodology - The first four years. Methodology, 5, 1-2.

Bamberg, M. (2003). Foreword. Em P. M. Camic, J. E. Rodhes \& L. Yardley (Eds.), Qualitative research in Psychology: Expanding perspectives in methodology and design (pp. ix-xi). Washington: APA.

Barbieri, V. (2002). A família e o psicodiagnóstico como recursos terapêuticos no tratamento dos transtornos de conduta infantis. Tese de Doutorado, Universidade de São Paulo, São Paulo.

Barbieri, V. (2008). Por uma ciência-profissão: o Psicodiagnóstico Interventivo como método de investigação científica. Psicologia em Estudo, 13, 575-584.

Bellak, L. (1974). The TAT, CAT and SAT in clinical use. New York: Grune \& Stratton. 
Camic, P. M., Rodhes, J. E., \& Yardley, L. (2003). Naming the stars: Integrating qualitative methods into psychological research. Em P. M. Camic, J. E. Rodhes \& L. Yardley (Eds.), Qualitative research in Psychology: Expanding perspectives in methodology and design (pp. 3-15). Washington: APA.

Conde, F. (1995a). Las perspectivas metodológicas cualitativa y cuantitativa en el contexto de la historia de las ciencias. Em J. M. Delgado \& J. Gutiérrez (Eds.), Métodos y técnicas cualitativas de investigación en Ciencias Sociales (pp. 53-68). Madrid: Editorial Síntesis S.A.

Conde, F. (1995b). Procesos e instancias de reducción/ formalización de la multidimensionalidad de lo real: processo de institucionalización/reificación social en la praxis de la investigación social. Em J. M. Delgado \& J. Gutiérrez (Eds.), Métodos y técnicas cualitativas de investigación en Ciencias Sociales (pp. 97-119). Madrid: Editorial Síntesis S.A.

Cunha, J. A., Freitas, N., \& Raymundo, M. G. (1986). Psicodiagnóstico. Porto Alegre: Artes Médicas.

Davila, A. (1995). Las perspectivas metodológicas cualitativa y cuantitativa en las ciencias sociales: debate teórico e implicaciones praxeológicas. Em J. M. Delgado \& J. Gutiérrez (Eds.), Métodos y técnicas cualitativas de investigación en Ciencias Sociales (pp. 69-83). Madrid: Editorial Síntesis S.A.

Finn, S. E. (1994). Using the MMPI-2 as a therapeutic intervention. Manuscrito Não-Publicado, Center for Therapeutic Assessment, Austin.

Friedenthal, H. (1976). Interrogatório, test de limites y señalamientos en el Test de Relaciones Objetales. Em R. F. de Verthelyi (Comp.), El Test de Relaciones Objetales de H. Phillipson (pp. 61-95). Buenos Aires: Nueva Vision.

Gelo, O., Braakmann, D., \& Benetka, G. (2008). Quantitative and qualitative research: Beyond the debate. Integrative Psychological and Behavioral Science, 42, 266-290.

Gutiérrez, J., \& Delgado, J. M. (1995). Introducción. Em J. M. Delgado \& J. Gutiérrez (Eds.), Métodos y técnicas cualitativas de investigación en Ciencias Sociales (pp. 25-50). Madrid: Editorial Síntesis S.A.

Hanson, D., \& Grimmer, M. (2007). The mix of qualitative and quantitative research in major marketing journals, 1993-2002. European Journal of Marketing, 41, 58-70.

Kvale, S. (2003). The psychoanalytical interview as inspiration for qualitative research. Em P. M. Camic, J. E. Rodhes \& L. Yardley (Eds.), Qualitative research in Psychology: Expanding perspectives in methodology and design (pp. 275-297). Washington: APA.

Lagache, D. (1974). La Psychanalyse comme science exacte. Psychologie Française, 19, 217-246.

Marecek, J. (2003). Dancing through minefields: Toward a qualitative stance in Psychology. Em P. M. Camic, J. E. Rodhes \& L. Yardley (Eds.), Qualitative research in Psychology: Expanding perspectives in methodology and design (pp. 49-69). Washington: APA.

McGrath, J. E., \& Johnson, B. A. (2003). Methodology makes meaning: How both qualitative and quantitative paradigms shape evidence. Em P. M. Camic, J. E. Rodhes \& L. Yardley (Eds.), Qualitative research in Psychology: Expanding perspectives in methodology and design (pp. 31-48). Washington: APA.
Morgan, C., \& Murray, H. A. (1935). A method for investigating fantasies: The Thematic Apperception Test. Archives of Neurology and Psychiatry, 34, 289-306.

Ocampo, M. L. S., Arzeno, M. E. G., \& Piccolo, E. G. (1986). O processo psicodiagnóstico e as técnicas projetivas (M. Felzenszwalb, Trad.) São Paulo: Martins Fontes. (Trabalho original publicado em 1979)

Ortí, A. (1995). La confrontación de modelos y niveles epistemológicos en la génesis e historia de la investigación social. Em J. M. Delgado \& J. Gutiérrez (Eds.), Métodos y técnicas cualitativas de investigación en Ciencias Sociales (pp. 85-95). Madrid: Editorial Síntesis S.A.

Pacheco Filho, R. A. (2000a). O método de Freud para produzir conhecimento: revolução na investigação dos fenômenos psíquicos? Em R. A. Pacheco Filho, N. Coelho Júnior \& M. D. Rosa (Orgs.), Ciência, pesquisa, representação e realidade em Psicanálise (pp. 235-270). São Paulo: Casa do Psicólogo: EDUC.

Pacheco Filho, R. A. (2000b). O debate epistemológico em Psicanálise (à guisa de introdução). Em R. A. Pacheco Filho, N. Coelho Júnior \& M. D. Rosa. (Orgs.), Ciência, pesquisa, representação e realidade em Psicanálise (pp. 15-42). São Paulo: Casa do Psicólogo: EDUC.

Proctor, R. W. (2005). Methodology is more than design and technology. Behavior Research Methods, 37, 197-201.

Rozin, P. (2009). What kind of empirical research should we publish, fund and reward? Perspectives on Psychological Science, 4, 435-439.

Santiago, M. D. E. (1995). Psicodiagnóstico: uma prática em crise ou uma prática na crise? Em M. Ancona-Lopez (Org.), Psicodiagnóstico: processo de intervenção (pp. 9-25). São Paulo: Cortez.

Tardivo, L. C. (2006). O atendimento em Psicodiagnóstico Interventivo na clínica-escola: o encontro entre os pacientes, os terapeutas e os estudantes de psicologia. Em N. A. Silva Neto \& D. M. Amparo (Orgs.), Métodos projetivos: instrumentos atuais para a investigação psicológica e da cultura. Anais do IV Congresso Nacional da Associação Brasileira de Rorschach e Métodos Projetivos (pp. 334-341). Brasília: Associação Brasileira de Rorschach e Métodos Projetivos.

Trinca, A. M. T. (2003). A intervenção terapêutica breve e a pré-cirurgia infantil: o Procedimento de Desenhos-Estórias como instrumento de intermediação terapêutica. São Paulo: Vetor.

Trinca, W. (1984). Processo diagnóstico de tipo compreensivo. Em W. Trinca (Org.), Diagnóstico psicológico: a prática clínica (pp. 14-24). São Paulo: E.P.U.

Vaisberg, T. M. A. (2004). Ser e fazer: enquadres diferenciados na clínica winnicottiana. Aparecida: Ideias e Letras.

Yanchar, S.C., Gantt, E. \& Clay, S. (2005). On the nature of a critical methodology. Theory and Psychology, 15, 27-50. 